\title{
Teachers' Perspectives on the Role of Incorporating Technology in Reading Comprehension Instruction for the Bagrut
}

\author{
Dr. Abdul Kareem Igbaria*, Ms. NidaArraf \\ Israel \\ *Corresponding Author: Dr. Abdul Kareem Igbaria, Israel

\begin{abstract}
The importance of teachers' perceptions on the use of technology in the teaching of reading comprehension for the Matriculation exam (Bagrut) is focused in this study. The purpose of this research is to study a teacher's own experience of using technology in the instruction of reading comprehension for the Bagrut exam. To achieve this purpose, the action research method was applied. Qualitative and quantitative data were collected. Qualitative data of the lessons of one experienced teacher with 11 years of experience in preparation for the Bagrut exam were collected. The achievements of two groups of 11th grade students (25 in each group) on reading comprehension tests attained in a traditional exam and in a computer-based exam were compared. The findings of the current research revealed the existence of a graduate change process in the teacher's perceptions. The initial stages of this process were characterized of cautious integration with specific considerations, however, a more open integration anchored in the teaching process was observed in later stages. Students' achievements were analyzed using $t$-Test, the results show a significant improvement ( $p<0.05)$ in the grades of the computer-based exam as compared to the grades of the traditional exam. The results of the current study demonstrate the benefits of using computer-based lessons in teaching reading comprehension for the Bagrut.
\end{abstract}

Keywords: Action research, Reading comprehension, Technology Bagrut, Teachers' Perceptions

\section{INTRODUCTION}

The Bagrut is a formal certificate issued by the Ministry of Education testifying that a student has successfully passed Israel's high school matriculation examination (Katz, 1995). In the English domain there are three different Modules at the three-point level A, B, and C. This study proposes to shed light on the issue of improving English comprehension (Rizqiya, 2013; Sabbah, 2015) within the framework of Bagrut preparations and teaching instruction by using technological techniques. The literature will be analyzed for improvement rates by using technology but will also analyze the traditional method of comprehension instruction for the sake of comparison.

The various teaching strategies that incorporate the use of technology in the teaching process will be hereby reviewed such as Informational and Communications Technology (ICT), online materials such as e-books and e-journals, and Internet English language educational websites (Young, 2008). In this teaching-learning environment, the role of the teacher is very important (Huang, 2014) in choosing and implementing the tools in class. Furthermore, teaching strategies should make the learning process innovative, interesting, and allow for more student autonomy in the choice of texts in order to promote learning intrinsic motivation.

The present study investigated teacher's experience in the context of teaching using technology, specifically teaching reading comprehension for the Bagrut.

The research question was: What are teacher's perceptions on the role of incorporating technology in the instruction of reading comprehension for the Bagrut?

The researchers hypothesized that teachers who incorporate technology in English teaching are motivated by creating an interactive, personal-adjusted learning environment for each student. The researchers also hypothesized that online computerized instruction in reading comprehension will improve the students' achievement scores in reading comprehension.

The data collection tools included observations and field notes of a teacher who teaches two threepoint groups (Modules A, B, C) studying in the same school, in the $11^{\text {th }}$ grade. In addition, a statistical 
analysis for the students' achievement was conducted using a t-Test in order to shed light on the contribution to students' achievement.

The results of this study could be useful for teachers, who are hesitant in using technology and intend to incorporate technology in their classes, to overcome their fears. This could also place teachers' technological skills development on the top of their priorities. In addition, the results could encourage and motivate schools to prepare more technologically equipped labs for the use of English teaching.

\section{LITERATURE REVIEW}

\subsection{Action Research}

The research process starts by identifying a problem or a special need of the teacher andlor his students; this process is characterized with circularity of planning, action and evaluation through reflection which gives the teacher the opportunity to learn about himself and his actions (Aubusson \& Gregson, 2008).

Corey (1953) hypothesized that the benefits of this research process (action research) could bring to more aware decisions and to the application of more effective teaching practices when research is a part of the regular teaching process. The involvement of the teacher and the students illuminates and gives interpretation to the teaching practices in a way that benefits the whole process and eventually creates knowledge to the teaching improvement (Shi, 2006).

\subsection{Technology-Assisted Instruction - Concepts and Views}

Lukow (2002) posited that although modern technology continues to evolve, educators need to pursue new technologies cautiously and adhere to the sound traditional pedagogical methods. By new technologies, she referred to Blackboard, websites, online resources, PowerPoint, discussion forums and expressed the fear that educators may engage in technicalities and lose sight of their main goal in educating students. Another concern is that students may get overwhelmed by the use of technology; hence, they may get frustrated with the various technological expertises and lose track of the learning goals. The way to combat this uncertainty of the students, according to Lukow, was to perform a survey amongst the students to find out their opinion on the subject as well as receive useful feedback. Findings of the survey show $70 \%$ student knowledge of the various technology usages such as emails, surfing the net, messaging, et cetera therefore, must be continued. However, teachers need to be sensitive regarding certain students of a low socio-economic status that may or may not have the means or the know-how of these new technologies in order to offer them assistance in gaining access and technological instruction (Lukow, 2002).

An in-depth thesis by Young (2008) reviewed the effect that computer technology use in the classroom had on students' grades, motivation, attitude, and attendance. The method used to evaluate these parameters was by administering teacher/student technology surveys. Findings from this research showed that teachers' technology use, students' technology use and overall technology use depended on the teacher's performance in using technology in the classroom, teacher's attitude towards technology and teacher's technological know-how. On the other hand, students were motivated by the use of technology; however, the usage had no significant positive impact on their grades or attendance. The conclusion drawn from this study was that in order for technology to be effective, teachers and students should receive the necessary training in order to make full use of these added assistive technologies. The tools currently available in many schools in the United States: Internet access, digital cameras, email, interactive whiteboards, laptop computers, LCD projectors, and course-specific software that support the curriculum (Young, 2008).

\subsection{Reading Comprehension-Assistive Technologies}

There is a large base of research which focus on the beneficial role of technology in reading comprehension. In the United States, contemporary language arts standards demand that students of all ages read authentic literature across genres (novels, memoirs, biographies, interviews) as well as the ability to write in different genres (Risqiya, 2013). Web-based technology enables the students to access wide sources of information. These informative websites and information opportunities provide contexts where students learn to interpret text and learn how to learn from the text. Yet there are issues to be researched as to the actual improvement in reading comprehension such as: what is 
the role of direct instruction in comprehension monitoring and fostering environment, how to enhance self-regulated reading, and does experience with a diverse array of texts impact motivational reading.

Reading, being an important skill in language learning and proficiency, includes "identifying, interpreting and evaluating ideas in terms of the mental content or total awareness of the reader" (Risqiya, 2013, p.31). According to Sabbah (2015) reading consists of two related processes word recognition and comprehension which is making sense of words, sentences and connected texts (encompasses reading the lines refers to reading verbatim, reading between the lines refers to understand the deeper meanings of thought and reading beyond the lines refers to usages of ideas for various circumstances and situations). Successful comprehension of a text encompasses employing various reading skills such as, making inferences, understanding the organizational pattern of the text, understanding the main idea of the text as well as the sub-ideas, and figuring out the relationship between the ideas and the details given in the text. There are various techniques that can enhance these comprehension capabilities one of which is called mind mapping. Mind mapping teaches learners to transfer the text into a visual map in order to visualize the relationships between the main ideas of a text and the sub-ideas in order to integrate the new information gained to prior knowledge.

Mind mapping allows for the reader to grasp the entirety of his notes at one glance and the easily places new information into the appropriate category. Furthermore, the learning and memory process is deeply connected to visual techniques which mind mapping provides. Both the Schema theory and the Constructivist theory are visible in mind mapping (Sabbah, 2015).

In order to further understand the positive impact of mind mapping on reading comprehension, Liu \& Chen (2008) tested the application of a computer-assisted concept mapping for improving English reading comprehension in 94-second language learners of different proficiency levels. PowerPoint mapping strategy was introduced to the learners in order to improve their reading comprehension. Through the ANOVA statistical analysis, it was found that the technique of computer-based concept mapping reading comprehension strategy was more effective to the high-level learners. Mind mapping is a technique that optimizes one's learning capacities and understanding of how the elements of complex structures are connected (Sabbah, 2015).

The last twenty years served as witness to movement towards the use of computers in second language studying around the world. The traditional paper and pencil examinations have been converted and computerized to suit the level and interests of the learners in many US classrooms. Lately, there has been a movement towards computerized adaptability tests as well as natural language processing to include the scoring of essays. Another testing which uses computerized testing is TOEFL (English language test), multiple choice tests, item creation and presentation, response collection and scoring, statistical analysis, storage, transmission and retrieval of information which serve as valuable learning tools for both teachers and students. The new TOEFL testing techniques pertain to reading comprehension - test takers are required to answer questions based on information from reading passages. Furthermore, the ease by which these reading comprehensions adaptive tests can be administered by teachers will enable much more practicing (Jamieson, 2005). Second language learning methods focused on the building of a dynamic learner-based constructivist model for reading comprehension which demands new and dynamic paradigms of assessment. Traditional comprehension testing relied on multiple choice tests and cloze but according to Heinz (2004), these tests are inadequate. The first step was to deliver the original texts and capture the students' recalls. The new model suggested for improving reading comprehension is a recall protocol or an expert system that contained the recall scoring (software exists on every computer desktop). The texts appeared, the student recalled and then an additional text appeared and so on. In the last step a scoring system was developed and finally, the expert system processed all the data to give the final score (Heinz, 2004).

\subsection{Internet Technologies and Reading Comprehension}

Research in computer assisted language learning reveals that students enjoy working with computerized courseware and have shown increased motivation in their learning patterns. It appears in research that students display various learning characteristics such as: self-directive, active, exploratory which occur in a very short period of time when learning on a multimedia interface. Internet Technology has revolutionized the traditional computer assisted language learning and has 
added numerous learning strategies, access to information sources (links to dictionaries and encyclopedias), cooperative learning, communication skills, and so on. It provides learners with flexibility, autonomy, interactivity and progress at individual paces. However, according to research by Chang and Lin (2019), learners' motivation degree may decline if they encounter material that does not arouse their interest, difficulty in understanding the assignment or inability to adjust to the online schedules. According to their research there is rationale for integrating explicit instruction of language learning strategies into classroom curriculums. The study presents a reading program strategy for reading comprehension for second language English learners called Multimedia Assisted Reading Training (SMART). The program is designed to train students to use four reading comprehension strategies: predicting, questioning, clarifying and summarizing.

Researchers have pointed out the benefit of teaching learners to use strategies. The underlying theory is by using strategies the learners develop the ability to become aware of their own knowledge construction process and by doing so they experience cognitive growth and better achievements. Learning strategies is not only beneficial to language learning but can be applied to all learning processes. They help to remember key points, distinguish between necessary and unnecessary information, think about main idea and comment on subject matter. Chang and Lin's article reviews a strategy which supports reading program and examines its effect on reading comprehension for second language English students. The program called SMART Strategy Oriented Multimedia Assisted Reading Training was set up on a modular object oriented dynamic learning environment (MOODLE) incorporated four reading strategies:

a. strategy of predicting - this strategy encourages predicting what the text is going to talk about or what will happen next - then they confirm or disprove their predictions during the reading process;

b. strategy of questioning - generating questions from important information in the text (for example when, why, who, where, what and how);

c. strategy of clarifying - students identify new vocabulary words, references, concepts that they difficulty understanding and then continue reading ahead to clarify he elements in the text; and

d. Strategy of summarizing - using the strategy students learn to identify, paraphrase and integrate important information in the text.

Research results showed an increase in achievement scores in reading comprehension after using the SMART strategies (a pretest and post-test was given). However, in spite of the improvement teachers need to continually introduce the students to these strategies, guided and instructed how to use them so they can be applied in the reading comprehension process (Chang and Lin, 2019).

\subsection{Ministry of Education Site's Views on Technology}

Beginning in the coming school year, the English language proficiency exam will vary from both the content and the technological aspect and the schools will have new tools for their choice: Skype - a conversation between the students and examiners or an online exam - in which the students will be required to relate to the video. The exams will enable students at all levels of study to practice spoken language in situations relevant to their daily lives. The new exams have been adapted to international standards and in the previous school year, a pilot was conducted using Skype and the online exam to examine the application technologies (Ministry of Education, 2017).

In the framework of 'Virtual Mentoring' - 1,500 students in 11th grade will receive online reinforcement classes by outstanding students with high English proficiency. In summary, the Ministry of Education is striving to integrate technology in the classrooms and is currently working on computerized lessons, laptops for students and teachers, a virtual library for the whole community (High Learn, Moodle), and technology instruction for teachers and more. The realization is that access to technology is an important tool in preparing the students for challenges of the twenty first century (Ministry of Education, 2017).

In light of the positive view of the Ministry of Education for computerized education in the classrooms, the current educational goals are in planning learning processes that will arouse the readiness and motivation of teachers to join forces in establishing meaningful and quality 
computerized lessons. For this purpose, teachers who participated in a pilot study in GaneiTiqvah (a town in the center of Israel) were given a laptop each (all the pupils have laptops) and a blog by EstiDoron, which gives insight to the learning atmosphere in the classroom. She states that she is not surprised anymore by the pupils using laptops in class. It is both a natural, essential process and serves as a pedagogical, organizational and systematic catalyst. On the whole, teachers are feeling much more competent with using technology. Not only is there an increase in the teachers' motivation but the lessons become more meaningful due to the connection to online information sources. The students work in a constructivist manner, the lessons last 90 minutes during which the class works quietly, no acts of violence and none of the children asks to leave the classroom, meaning $80 \%$ of the time is devoted to computerized studying. English teachers published their response to computers in the classroom as having a positive effect on the learning process and an increase in their achievement scores.

\subsection{Teachers' Attitudes towards Online Technology}

The digital age has arrived in classrooms today around the world as well as in Israel. The Ministry of Education is currently putting into place reform strategies in education allowing for the student to be more autonomous, have more choice in choosing subjects on the curriculum, and presenting assignments in the various digital formats such as pictures, video movies, and presentations and so on (Ministry of Education, 2017). Children are usually the first to capture new technologies beginning with smart phones, applications, websites, computers, laptops, tablets, and iPads and therefore adults need to keep up with technology in order to monitor their education. This is the case with technology in the classroom where teachers need to receive instruction from computer technicians in order to fully utilize all the available technology in the school. On the one hand, children display both high motivation in learning and enthusiasm in using technology but on the other hand, teachers report that they feel threatened by the advantage children have over them in the use of technology. Furthermore, teachers complain that the use of computers in the classroom can cause disturbances in the lesson especially if there are not enough laptops for every pupil (Binnur, 2009).

In general, teachers' attitudes towards integrating technology in the classroom are positive. Teachers have expressed an increase in motivation and self-efficacy both on their own part but for the students as well. However, despite the obvious advantages, teachers complain about the workload which has increased and also about dilemmas as to how to construct a lesson incorporating the various digital tools. They are confronted with new techniques and new options in order to integrate technology in their traditional lessons. There is a lot going on in the classroom with the various tasks and digital options which may cause disciplinary problems for the teacher. Some of the teachers still feel intimidated by either by their not receiving enough instruction or by the students' higher level of competency with computers (Paz \&Salant, 2010).

These current problems are being addressed by the Ministry of Education - new lesson plans for integrating technology in the classrooms by the teacher using a class computer connected to a screen whereby children can follow the lesson via an Internet link. In addition, teachers will receive professional development course in technology integration, development of new pedagogical techniques, and support for teachers as well as school financing (Ministry of Education, 2017).

The joint between the Ministry of Education and representatives of the business and social sectors project to give each teacher in Israel a mobile computer brought significant changes in the actual usage of computers in the classroom. Findings from this research revealed several points:

a. an increase in teachers' motivation and an increase in the number of lessons that integrated technology in the classroom (before receiving computers approximately 50\% of teachers did not integrate computer usage in the classroom);

b. teachers admitted that the computers assisted them in improving teaching methods;

c. better utilization of time in the classroom; and ability to show examples on the computer allowed that to individualize lesson plans according to the progress, interests and capabilities of each student (Paz \&Salant, 2010).

Teachers believe that incorporating technology in the classroom allows for the introduction of innovative teaching and learning techniques. The students are also able to develop a self-instruction 
ability which decreases the teachers' workload as well as cooperative learning and meta-cognitive thinking processes. Having the capability of independent study enables the teachers to have more free time in planning strategies and in focusing on the weaker students. Levels in increased usage of computers were noticed in a number of fields: literary searches for academic information on specialized websites, use to Internet forums and chat rooms to communicate thoughts and advice with colleagues, amount of material retrieved from Internet sources, information retrieval on administrative topics, and use of information technology to edit, process and utilize data from databases and websites (Paz \&Salant, 2010).

Although the conclusion that can be derived from the literature review is that using the computer in the instruction can bring many benefits to the teaching-learning environment, many teachers still hesitate this use and still, for specific contents such as reading comprehension, wonder what implications this use can bring to the teacher him/herself and to students' achievements.

The research questions in the present research reflect a teacher's effort to investigate her teaching in two different teaching-learning environments: with and without the use of the computer.

\section{Research Question:}

What are teacher's perspectives on the role of technology in the instruction of reading comprehension for the Bagrut?

Two explicit questions were examined:

1. What is the teacher's perspective on the role of technology when teaching reading comprehension for the Bagrut and which characteristics shape this perspective?

2. What are the implications of teaching reading comprehension with technology on students' achievements?

\section{Hypotheses:}

Hypothesis 1: It is hypothesized that the teacher's perspective is hesitative and will improve gradually.

Hypothesis 2: It is hypothesized that there is a positive connection between integrating technology and students' achievements in reading comprehension.

\section{MeTHOdOLOGY}

\subsection{Research Aims}

The purpose of this study was to reveal teacher's perspectives on incorporating technology in the instruction of reading comprehension for the Bagrut. The dilemma of what is the best way to teach reading comprehension for the Bagrut motivated the researchers in the present study to conduct action research. The action research approach was implemented and included collecting qualitative and quantitative data based on lessons spread throughout the school year (2017-2018) in reading comprehension in 2 classes $\left(11^{\text {th }}\right.$ grade) in the same school. The lessons were in reading comprehension by giving the students a passage to read accompanied by answering questions. The first group was taught reading comprehension in the traditional way without using technology and was tested before the Bagrut with a traditional exam. The second group was taught reading comprehension while the instruction included using the computer and was tested before the Bagrut with a computer-based exam.

\subsection{Research Tools:}

1. Observation is a data-collecting tool commonly used in the qualitative research in general and in action research specifically. The teacher, who was one of the researchers in the present study, and the other researcher managed field notes in order to obtain detailed view from the research field. Those notes gave insights regarding the following aspects:
a. Teacher's management of the lesson
b. The challenges that the teacher faces
c. The ways those challenges are overcome 
The researchers' field notes from the two classes were collected and analyzed.

The field notes supplied insights regarding teacher's actions during the lessons and documented important events regarding the topics studied in the lessons.

2. The quantitative data acquired from students' grades in both exams.

The scores from the two tests were statistically compared using a t-Test to get more insights about the implications of using technology on students' test scores.

Module C test that the students were tested on. Taken from the Stay Up To Date, English Inspectorate website:

http://cms.education.gov.il/educationcms/units/mazkirut_pedagogit/english/inspectoratesdesk/whatsne w.htm

Moule C- Test- Hard Copy

https://meyda.education.gov.il/sheeloney_bagrut/2016/6/HEB/16382.PDF

\subsection{Research Method:}

The teacher who participated in this study is a teacher who taught two, three-point Bagrut classes in the same school aiming for the Module A, B and C Bagrut examinations.

The method implemented in this research was the action research approach including both qualitative and quantitative data. Two separate lessons were administered - the pilot group received a lesson in the traditional manner namely a printed text that was a short story. The teaching approach was frontal - teacher asked questions regarding the text, related topics were brought up, and the main and subordinate ideas were discussed. Vocabulary was dealt with and a writing activity such as a short summary of the text in 2-3 sentences was administered; the control group received a computerized online reading assignment - students had use of the Internet for definitions and for added information such as hypertexts. The online lesson included new sources or prior knowledge, higher levels of inferential reading and self-regulated navigation strategies.

The time that was allotted to this research was full academic year starting September and ending July.

\subsection{Data Analysis}

The data analysis included:

1. The analysis of the qualitative data from the lessons' observations and from the field notes. The data was analyzed using categorization analysis in order to get insights regarding the teacher's perspectives on the use of technology in the lessons.

2. The t-Test analysis of the students' tests scores.

\subsection{Participants}

\section{Research Participants:}

- One English teacher with 11 years of experience in preparing for the Bagrut examinations.

- Two classes (11 grades) in a high school in the northern district of the country - 25 students in each class.

At the beginning of the year, the students got an explanation and guidelines from the teacherresearcher regarding the instruction method that will be implemented in their classroom and the data collection.

\section{FINDINGS}

The main purpose of the study was to address teaching characteristics of the process when teaching reading comprehension with and without incorporating technology. It is known that an important feature in English language proficiency and an important part of success in the Bagrut examinations is reading comprehension. The rationale underlying the investigation was to assess the best way to teach reading comprehension for the Bagrut. The first class received a traditional lesson of reading through the passage and addressing vocabulary and comprehension issue. The second class received a lesson 
with the use of computers - the students could use electronic mind maps, highlight or gloss vocabulary words, use the Internet for definitions or more extensive information available on online resources. The information gathered from these four activities revealed.

The first period was accompanied with hesitation and worries about technical difficulties. Though the teacher was qualified to use the computer, still she expressed worries about unexpected technical difficulties that might come up and cause time delay in the lesson. However, students' engagement in the computer-based lessons was much greater than in the other regular teaching class which encouraged the teacher to try harder to cope with those difficulties.

At the beginning of the year, as the teacher started preparing the students for the Bagrut exam, she noticed that the passive role of the students was hindering her teaching and she became more aware that the more paper texts (hard copies) she handed out, the less the motivation of the students. This traditional method of frontal teaching was taking a toll on their comprehension, understanding, motivation and most important of all, their grades.

The teacher chose to try out technology and see how it affected students' learning of the material.

According to the teacher-researcher field notes (Appendix i): "The idea was to project the text (soft copy) that I wanted to teach on the white screen and have the students write the answers in their notebooks. After the first lesson, a few students came up to me and told me that it was much easier to learn this way because they were able to follow the text better and as they answered the questions, I highlighted the lines and paragraph that they got the answer from. The next lesson, one of the weak students in the class asked if she could highlight the answers, while they go over them. I agreed of course and allowed her to do so and helped her explain to the class the answers and strategies they used in order to be able to answer correctly."(Thursday, $7^{\text {th }}$ Nov. 2017)

In both classes the teacher used the same texts, strategies and procedures to teach the material that was required for the Bagrut exam. However, the class that was using the hard copy was less motivated and received significantly lower grades than their counterpart.

Along time, through this experience, teacher's perspective of teaching for the Bagrut exam has changed she started to realize that incorporating technology in her teaching will benefit her students.

\section{Reading comprehension using Internet technologies versus reading comprehension without computer access}

Basically, conclusions were based on the results of the two tests which were concise written summaries of identical passages. The pupils from the computer-based class demonstrated significant improvement over the other group in two distinctive skills

a. Reading comprehension

b. Integrating new vocabulary words in the summary/essay.

The reason for this growth in comprehension demonstrated by the first group is due to the usage of Internet databases for extra knowledge on the given passage.

The students' grades (Appendix ii) in the final exam were statistically compared.

The t-Test statistical analysis (Appendix iii) of the students' grades in the two classes show a significant improvement $(\mathrm{p}<0.05)$ in students' grades in the classroom using computer-based lessons.

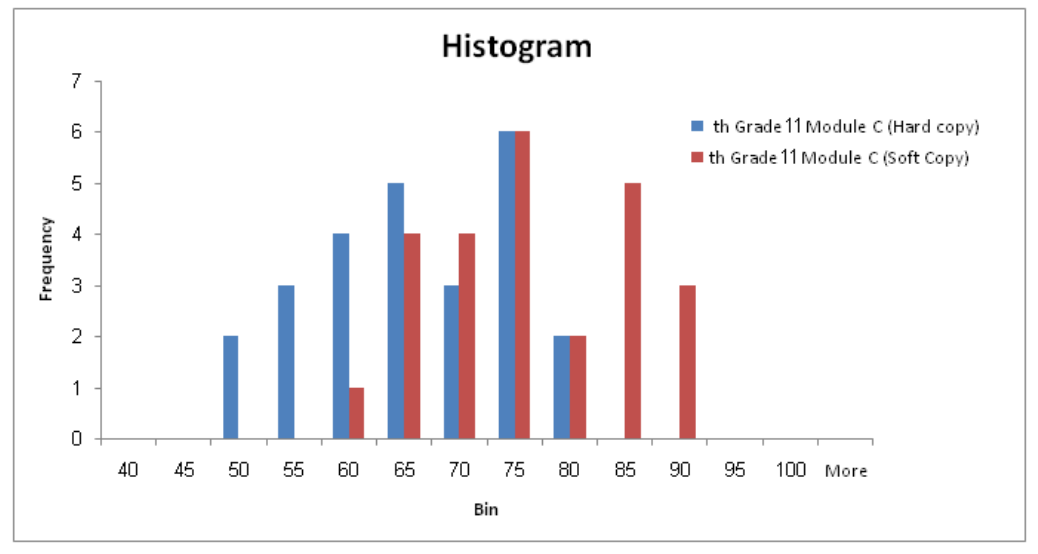

The t-Test analysis results: Figure1: t- Test histogram 


\section{DISCUSSION}

\subsection{Traditional Methods}

Grabe (1997) regards comprehension as a dynamic process whereby new meaning is reconstructed from a message or a text. Concept-oriented reading instruction, comprehension strategies (induces reading independence), motivation strategies (encourages choices, activities, interesting texts) proved more effective than just the traditional method (Butler et al, 2010). As mentioned above comprehension occurs by extracting and constructing meaning from the text, however, despite this data, only $2 \%$ of teachers' instruction time was dedicated to comprehension (Butler et al, 2010). Teachers' emphasis basically focused on vocabulary instruction and story comprehension instead of discussing meaning and the main points of the text - the pupils' role in such a classroom scenario is that of a passive listener. Reading comprehension involves more than exposure to books, it involves incorporating both complex and multiple strategies (RAND report 2002) such as:

a. deliberate goal-directed attempts to control and modify readers' attempt to decode text;

b. direct comprehension instruction strategy (explain complex cognitive skills and develop effective strategies)

c. explicit instruction - supported by awareness of content and strategic thinking.

In the present research, the teacher applied the teaching strategies when teaching reading comprehension gradually realizing that those strategies are being performed in a better way in the computer based classroom than in the regular classroom.

\subsection{Advantages of Online Reading Comprehension}

Teaching comprehension on computers has text features that enhances vocabulary knowledge. Vocabulary is a key element in comprehension by allowing non-linear hypertext, links to added knowledge, academic databases, dictionaries, interactive texts, audio, video, glossing and highlighting. As pupils' transition from tradition to electronic texts, the possibilities no longer linear as in the traditional method but are horizontal as the Internet leads pupils in all directions as the hyperlinks take pupils to multiple websites.

The reasons for this improvement in achievements are the access to added knowledge sources, webbased activities are more interesting and therefore motivating, higher levels of thinking and problemsolving skills are required, multiple search engines, meaningful activities, communication with larger audiences (teachers, parents, social media) and self-governed learning (Riskiya, 2013). Mind mapping (Liu \& Chen, 2008) is recognized by researchers as an important tool for enhancing reading comprehension.

\subsection{Research Limitations}

The present study is a study conducted with the action research approach. This approach enables the teacher to look deeper into her own teaching practices and into the students' learning, however, since the teacher plays the role of the teacher and one of the researchers at the same time, the ability to generalize the findings is limited.

Some of the challenges that the teachers would face are the lack of equipment at school. If there is no access to technology at school, then the teachers will find it extremely difficult to teach the required material technologically. Teachers may also not have the proper training that is required in order to use the equipment (if it is available to them) thus rendering them to use the traditional face to face method. Furthermore, similar to all public schools there are budgetary limitations. Most teachers are very keen about using technology, identifying the advantages in pedagogy, student tracking and teacher workload. Educators believe that budgetary limitations restrict their plans for executing and sustaining an efficient technology network. This includes effective ongoing professional development courses for teachers in using new technology, without which much of the investment in education is lost.

Inadequate Professional Training: New educational challenges face governments nowadays in order to cope with $21^{\text {st }}$ century requirements in preparing the students accordingly. This is particularly important where English is studied as a foreign language. Reforms need to be put in place which hail 
action-based learning which liberates the traditional static syllabus and traditional approach. Moreover, technology should be introduced in the classroom for every lesson alongside the traditional teaching techniques. In order to achieve these educational goals successfully, teachers require the proper training courses to both apply new teaching techniques as well as choosing the appropriate digital measures to enhance learning (Kukulska-Hulme, 2000).

Teachers' resistance to change: A study by Butler et al, (2010) points out that students need to have greater autonomy in the learning process in order to express their innovative, creative and inspirational ideas as well as develop intrinsic motivation. However, most language teachers are not proficient in the use of technology. Furthermore, teachers are reluctant to give up traditional instruction models whereby teachers preselect target vocabulary and provide them in a uniform fashion.

\section{SUMMARY AND RECOMMENDATIONS}

Internet Technology provides teachers with flexibility, autonomy, interactivity and progress at individual paces which represent all the necessary learning skills to prepare pupils for the $21^{\text {st }}$ century challenges. Both the scientific literature and the results of the tests point out the many beneficial factors of using technology in the classroom. However, although proceeding in the direction of technology is the natural course of events and has potential in improving reading comprehension as well as language learning to new heights, the transition needs to be applied in educational environments with caution. Primarily, students are far more proficient in technological literacy than teachers, therefore teacher instruction and guidance in computer literacy should be administered. Next, the heterogeneity of the classroom involves pupils of various socio-economic levels; therefore, equipment needs to be assessed both for school usage as well as in the homes in the form of computers, tablets or smart phones.

\section{APPENDICES}

\section{1. (Appendix i) Sample Field Notes}

\subsubsection{Lesson Based on A Hard Copy (Traditional Method) of Teaching}

When preparing for a traditional lesson, I have many things to think of: which material to teach, (choosing the most interesting Bagrut text to teach so the students don't get bored), how many copies I need to make and staple and how can I make the lesson fruitful and simple using this method of instruction for my students.

This method of instruction is always the toughest on the students; they find it boring and uneventful. So, I make it a point to teach a full 45 -minute lesson with as much activity as possible. The main points during this lesson are for the students to focus on reading the text and answering the accompanyingquestions as quickly and as accurately as possible. The way I manage to teach them this is by getting them to skim over or scan the text and see what things are obvious or stand out to them such as dates, numbers, names etc. and highlight or underline them.

I have some of the students come up to the board and write what stood out to them. I then have them read over the text and help them out wherever it's needed. After all, this is done, they start by answering the questions that come with the text, and I remind them that all the things that they have highlighted or underlined are usually asked about in the text and for them to refer back to them when they answer the questions.

One of the most evident and recurring events in my class is that I have noticed is that most of the students don't have enough time to write the answers, even after we go over them in class and I write all the answers on the board. This, in turn, makes them frustrated and unmotivated because they feel like they were not able to complete the questions and so feel like that they have failed this part of the lesson, no matter how much I praise and encourage them.

This method of teaching is also very binding; it restricts the student to "pen and paper", which is something that is not very helpful when it comes to teaching the material that is required.

Teaching the writing part of the Module $\mathrm{C}$ Bagrut exam is a daunting task when it comes to the students. There are certain methods and strategies that must be presented to the students for them to 
write a coherent and legible essay. Frontal teaching makes teaching writing very difficult because there is so much to write and explain. I found that my students tire quickly and lose all motivation to do the writing task. Having to use white out or having to erase all the time is something that is timeconsuming and my students hate to do. They also found it difficult to have to keep flipping pages in order to look back at all the methods and strategies that I taught them. I also had to explain the same thing repeatedly to so many students, which was tiring and frustrating.

\subsubsection{Lesson Based on a Soft Copy (Non-Traditional Method) of Teaching}

When preparing for a computerised lesson, I have to use my computer. I choose a text that is suitable for the level of the Bagrut that I will be teaching (Module A, B or C).

When I teach, I project the text on the board and go over the methods and strategies that come along with each Module. The students look at the screen and follow everything that I teach. I ask them to confirm understanding and the ones that they don't understand to ask me questions so I can further explain. This method makes it easier for me to explain what is not understood and gives me the opportunity to further clarify to the whole class what needs to be understood.

I then ask a student to come up to the screen and (using the mouse) highlight the methods and strategies that I explained to the class. Another student types the important points or notes that come along with that Module.

One of the things that I ask the students to do in any Module is to highlight or underlineanything that stood out to them, such as dates, numbers, years, names etc. By having the text on the screen, I can have students read or go over the text and have them come up to the screen and highlight what stood out to them. We use different colours for different numbers, dates, names etc....

The questions that come with the text are then answered on the screen too. I have the students write the answers only in their notebooks and choose a few (after they have completed the answering the questions) students to type their answers on the computer. By doing this, I discovered that many of the students wanted to type in their answers and raised their hands to be picked in order to do so.

This technique of teaching also helps me increase the amount of material that needs to be taught in a 45-1.5 hour lesson by projecting the answers to the questions on the screen. They can see where they went wrong and correct their mistakes. I don't have to keep erasing the board and the students don't have to write so much in their notebooks.

This way of teaching the material that is required for the Bagrut is so much easier and much more fruitful and productive for the students. By conducting my lesson this way and having them be part of the teaching process the students greatly benefit and are much more likely to do the work that is required of them in class.

The writing section of the material is taught by having the students come up to the board and complete a table which shows how the writing part of the Bagrut is supposed to be (after I show them the strategies) I then display the steps to coherent writing and have them writetheirs on their own. They send me their work via Google Drive and I correct and comment on each one of the written pieces that were sent to me (a process that takes much less time and effort than doing it by hand).

At the end of the lesson, I send the text that we studied in class to all my students via email and this way they have it as a computer file and are less prone to lose the text as they would if I had given them a hard copy.

\section{2. (Appendix i i) Grades}

Grade division and outcome:

\begin{tabular}{|l|l|l|}
\hline Student & Module C (Hard copy) $11^{\text {th }}$ Grade & Module C (Soft Copy) $11^{\text {th }}$ Grade \\
\hline 1 & 67 & 75 \\
\hline 2 & 70 & 80 \\
\hline 3 & 75 & 83 \\
\hline 4 & 60 & 72 \\
\hline 5 & 65 & 70 \\
\hline 6 & 55 & 63 \\
\hline 7 & 63 & 70 \\
\hline
\end{tabular}


Teachers' Perspectives on the Role of Incorporating Technology in Reading Comprehension Instruction for the Bagrut

\begin{tabular}{|l|l|l|}
\hline 8 & 74 & 85 \\
\hline 9 & 66 & 74 \\
\hline 10 & 50 & 60 \\
\hline 11 & 61 & 68 \\
\hline 12 & 53 & 65 \\
\hline 13 & 77 & 85 \\
\hline 14 & 60 & 90 \\
\hline 15 & 76 & 86 \\
\hline 16 & 56 & 67 \\
\hline 17 & 72 & 88 \\
\hline 18 & 58 & 75 \\
\hline 19 & 74 & 83 \\
\hline 20 & 71 & 80 \\
\hline 21 & 62 & 71 \\
\hline 22 & 50 & 65 \\
\hline 23 & 73 & 82 \\
\hline 24 & 65 & 75 \\
\hline 25 & 55 & 63 \\
\hline
\end{tabular}

The grades were allocated according to the grading system that is used in the Ministry of Education's English Inspectorate Website. The final grade is out of 100.

\section{3. (Appendix iii) t-Test Data}

t-Test: Two-Sample Assuming Equal Variances

\begin{tabular}{|l|l|l|}
\hline & Variable 1 & Variable 2 \\
\hline Mean & 64.32 & 75 \\
\hline Variance & 70.72667 & 76.83333 \\
\hline Observations & 25 & 25 \\
\hline Pooled Variance & 73.78 & \\
\hline Hypothesized Mean Difference & 0 & \\
\hline df & 48 & \\
\hline t Stat & -4.39599 & \\
\hline P(T<=t) one-tail & $3.04 \mathrm{E}-05$ & \\
\hline t Critical one-tail & 1.677224 & \\
\hline P(T<=t) two-tail & $6.08 \mathrm{E}-05$ & \\
\hline t Critical two-tail & 2.010635 & \\
\hline
\end{tabular}

\section{REFERENCES}

[1] Aubusson, P. \& Gregson, R. (2008). Self-Study, Teacher-Researcher and Action Research: Three Sides of a Coin? In Aubusson, P. \&Schuck, S. (Eds.) Teacher Learning and Development, Springer Netherlands, 195-208.

[2] Binnur, G. (2009). Effect of Technology on Motivation in EFL Classrooms Online Submission, Turkish Online Journal of Distance Education--TOJDE v10 n4 Oct 2009

[3] Butler, S., Urrutia, K., Buenger, A., \& Hunt, M. (2010). A review of the current research on comprehension instruction. Contract No. ED-08-CO0123). National Reading Technical Assistance Contract No. ED-08-CO0123). National Reading Technical Assistance Center, RMC Research Corporation. Retrieved from US Department of Education http://www2.ed.gov/program/readingfirst/ support/compfinal.pdf.

[4] Chang, M. M., \& Lin, M. C. (2019). Experimental Study on Strategy-Oriented Web-Based English Instruction for EFL Students. Journal of Educational Computing Research, 56(8), 1238-1257.

[5] Corey, S. M. (1953). Action Research to improve school practices. New York: Teachers College Press.

[6] Grabe, W. (1997). Reading research and its implications for reading assessment (Language Teaching Resource Center Paper). Flagstaff: Northern Arizona University.

[7] Heinz, P. J. (2004). Towards enhanced second language reading comprehension assessment: Computerized versus manual scoring of written recall protocols. Reading in a foreign language, 16(2), 97.

[8] Huang, H. C. (2014). Online versus paper-based instruction: Comparing two strategy training modules for improving reading comprehension. RELC Journal: A Journal of Language Teaching and Research, v45 n2 p165-180. 
[9] Jamieson, J. (2005). Trends in computer-based second language assessment. Annual Review of Applied Linguistics, 25, 228-242.

[10] Katz, Sh. (1995). Difficulties and problems in reading comprehension in a foreign language within speaking- Hebrew students. Shanin, pp 73-84

[11] Kukulska-Hulme, A. (2000). WorldCALL: Global Perspectives on Computer-Assisted Language Learning-Edited by Robert Debski and Mike Levy, Swets\&Zeitlinger, Lisse, The Netherlands, 1999. 363 pp. ISBN 90-265-1555-3. Computers \& Education, 35(4), 330-332.

[12] Liu, L. and Chen, C. 2008. The Effects of Computer-Assisted Concept Mapping on EFL Students' English Reading. In Luca\& E. Weippl (Eds.), Proceedings of World Conference on Educational

[13] Multimedia, Hypermedia and telecommunications 2008 (pp. 4724-4739).

[14] Lukow, J. E. (2002). Students Attitudes Toward the Use of Technology in the Classroom. Department of Human Performance and Health Promotion, University of New Orleans. Onwuegbuzie,

[15] Ministry of Education, (2017). Revised English Curriculum Principles and Standards Learning English as an International Language for All Grades. Jerusalem: Ministry of Education

[16] Paz, D. and Salant, A. (2010). Integrating Laptops in the Educational System: Scientific Survey, Tel-Aviv: MofetInstitute, 224 pages

[17] RAND Reading Study Group. (2002). A research agenda for improving reading comprehension. Theoretical models and processes of reading, 4, 720-754.

[18] Risqiya, R. 2013. The use of mind mapping in teaching reading comprehension. ELTIN Journal. Vol. 1, no.1, pp. 32-43.

[19] Sabbah, S. S. (2015). The Effect of College Students' Self-Generated Computerized Mind Mapping on Their Reading Achievement. International Journal of Education and Development using Information and Communication Technology (IJEDICT), 2015, Vol. 11, Issue 3, pp. 4-36

[20] Shi, L. (2006). Students as research participants or as learners? Journal of Academic Ethics, 4, 205-220.

[21] Young, R. (2008). Using technology tools in the public-school classroom. University of Wisconsin: Unpublished Master's Thesis

\section{AUTHORS' BIOGRAPHY}

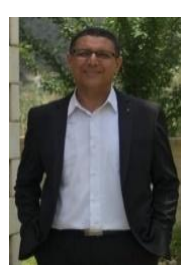

Dr. Abdul Kareem Igbaria, is a lecturer at the Sakhnin College for Teacher Education in the English Teachers' Training Department in Israel. Dr. Igbaria received his Master's Degree in TESOL from the School for International Training in Vermont in the United States, and completed his doctorate in TESOL from Irbid University in Jordan.

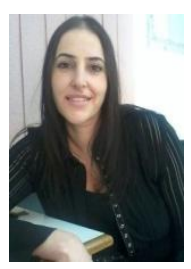

Ms. NidaArraf, carries a Masters degree in English Language and Literature, specializing in teaching EFL to LD and weak students through the use of technology. She currently teaches at Shiffman High School, Haifa and Ono Academic College, Haifa where she is department head. The research field that Ishe is interested in is technology in education focusing on LD and weak EFL learners.

Citation: Dr. Abdul Kareem Igbaria, Ms. NidaArraf. "Teachers' Perspectives on the Role of Incorporating Technology in Reading Comprehension Instruction for the Bagrut" International Journal of Humanities Social Sciences and Education (IJHSSE), vol 7, no. 5, 2020, pp. 1-13. doi: http://dx.doi.org/10.20431/23490381.0705001 .

Copyright: () 2020 Authors. This is an open-access article distributed under the terms of the Creative Commons Attribution License, which permits unrestricted use, distribution, and reproduction in any medium, provided the original author and source are credited. 